\title{
Utilização de Geotecnologias para análise de uso da terra no PA Matupi, Amazonas
}

\begin{tabular}{|c|c|}
\hline Rodrigo Nascimento Correia & $\begin{array}{l}\text { Universidade Federal do Amazonas. Curso de graduação em } \\
\text { Engenharia Ambiental. Humaitá, AM, Brasil } \\
\qquad \text { E-mail: correia.rodrigo93@hotmail.com }\end{array}$ \\
\hline Matheus Lucas Maciel Leal & $\begin{array}{l}\text { Fundação Universidade Federal de Rondônia, Porto Velho, } \\
\text { RO, Brasil. } \\
\text { E-mail: lucax.leal@gmail.com }\end{array}$ \\
\hline Viviane Vidal da Silva & $\begin{array}{l}\text { Universidade Federal do Amazonas. Programa de Pós- } \\
\text { Graduação em Ciências Ambientais. Humaitá, AM, Brasil. } \\
\text { E-mail: correia.rodrigo93@hotmail.com }\end{array}$ \\
\hline $\begin{array}{l}\text { Tatiana Acácio da Silva } \\
\text { Wanessa Monteiro Fernandes }\end{array}$ & $\begin{array}{r}\text { Universidade Federal do Amazonas. Humaitá, AM, Brasil. } \\
\text { E-mail: tatianaacacio1909@gmail.com } \\
\text { mfwanessa@gmail.com }\end{array}$ \\
\hline
\end{tabular}

Recebido: 28 out. 2017. Revisado: 26 jan. 2018. Aceito: 26 jan. 2018.

DOI: http://dx.doi.org/10.21674/2448-0479.41.107-118

\section{Resumo}

Os assentamentos rurais estão entre as principais variáveis relacionadas a devastação da Amazônia Legal, principalmente em função da prática da atividade pecuária. Esse cenário tem sido estudado por diferentes áreas como biologia, ciências sociais e geociências. Este artigo objetiva analisar e quantificar o uso e ocupação da terra no Projeto de Assentamento Matupi, localizado na mesorregião do Sul Amazonense, no município de Manicoré/AM. Foram delimitadas como classes de uso da terra para este estudo: Floresta, Pastagem abandonada e Pastagem. Utilizou-se uma cena do satélite Landsat-8 sensor OLI, e com o auxílio do software de Sistema de Informações Geográficas (SIG), QGIS 2.8.1, obteve-se a classificação digital da cena da área em estudo, gerando como produto um mapa temático. Verifica-se que $42,35 \%$ da área total do assentamento é composta por Floresta, $23,43 \%$ de Pastagem abandonada e $34,22 \%$ de Pastagem. Desta forma, pode-se concluir que esta localidade apresenta alto índice de desmatamento, o qual se deve a predominância das classes de Pastagem, que totalizam $57,65 \%$ da área total do assentamento.

Palavras-chave: Assentamentos Rurais. Amazônia. Geociências.

\section{Abstract}

\section{Use of geotechnologies for soil analysis in the Settlement Project}

Matupi, Amazonas. Rural settlements are among the main variables related to the devastation of the Legal Amazon, mainly due to the practice of livestock activity. This scenario has been studied by different areas such as biology, social sciences and geosciences. This paper aims to 
analyze and quantify the use and occupation of land in the Matupi Settlement Project (PA), located in the mesoregion of the Amazonian South, in the municipality of Manicore / AM. They were delimited as land use classes for this study: Forest, Abandoned Pasture and Pasture. A scene from the Landsat-8 satellite OLI satellite was used, and with the aid of the Geographic Information System (GIS) software, QGIS 2.8.1, the scene classification was obtained digitally, generating as a product a themed map. It is verified that $42.35 \%$ of the total area of the settlement is composed of Forest, $23.43 \%$ of Abandoned Pasture and $34.22 \%$ of Pasture. In this way, it can be concluded that this locality has a high rate of deforestation, which is due to the predominance of Pasture classes, which are $57.65 \%$ of the total settlement area.

Keywords: Rural Settlements. Amazon. Geosciences.

\section{Introdução}

As transformações antrópicas que vem ocorrendo na Amazônia Legal são consequências da expansão da fronteira agrícola e da criação de assentamentos rurais, onde ambos estão incentivando os processos de ocupação. A região vem se tornando o principal alvo no que se refere à implementação da reforma agrária, principalmente pelo crescimento da sua população, bem como da área destinada a este fim (LE TOURNEAU; BURSZTYN, 2010). Embora a política de assentamentos rurais tenha início em Rondônia, o Amazonas, em particular em sua porção sul, também conta com a presença de projetos tradicionais, como os Projetos de Assentamento (PA) Acari no município de Novo Aripuanã, Juma no município de Apuí e Matupi no município de Manicoré. As modalidades extrativistas também estão contidas em grande número no estado (ALENCAR et al., 2016).

A região Sul do Amazonas, vem se consolidando como nova área de expansão de fronteira agropecuária e concentrando a maior parte das novas áreas de desmatamento no estado (MACEDO; TEIXEIRA, 2009). Silva (2012) salienta que a atividade preferida dos assentados é a pecuária, a qual requer a conversão de áreas de floresta, colocando em questão a viabilidade ambiental destas áreas. Além disso, fatores sociais enfrentados pelos assentados criam uma condição favorável ao desmatamento local. Alguns destes problemas são a falta de assistência técnica, ausência de crédito e perda de safra de produção (CALANDINO et al., 2012).

Diante do exposto, o objetivo do trabalho consiste no estudo quantitativo do uso e ocupação do solo no Projeto de Assentamento Matupi e identificar sua real contribuição para o desmatamento. A área de estudo apresenta um histórico recente de desmatamento, uma vez que $91 \%$ dos seus lotes encontram-se com taxas acima do permitido pelo Código Florestal (LEAL et al., 2017). Para esta análise, é indispensável o auxílio de geotecnologias como o Sistema de Informação Geográfica (SIG) e Sensoriamento Remoto (SR) ambas ferramentas de Geoprocessamento. Através destas, pode-se identificar e quantificar de espacialmente os possíveis focos de desflorestamento na região.

\section{Assentamentos Rurais e Meio Ambiente}

De acordo com o Instituto Nacional de Colonização e Reforma Agrária - INCRA (2016) Assentamento Rural é denominado como, o conjunto de unidades agrícolas independentes entre si instaladas pelo órgão do governo, onde originalmente existia um imóvel rural que pertencia a um único proprietário. Estas unidades territoriais são chamadas de parcelas, lotes ou glebas, e estas 
unidades são doadas as famílias sem condições econômicas para adquirir e manter um imóvel rural por outras vias.

Uma das características que se pode observar em um Assentamento Rural, está relacionada com a sua potencialidade no modo de produção. As atividades produtivas nestas áreas são fomentadas por políticas públicas, que visam o desenvolvimento econômico e autonomia dos assentados (SILVA, 2012). Com o envolvimento de políticas públicas para assistência aos assentados, o INCRA vem utilizando procedimentos mais criteriosos para a distribuição de lotes e seleção de beneficiários. As novas metodologias usadas baseiam-se na observação de dados de produção, além da identificação do caráter extrativista da população. Esta mudança de conduta do INCRA visa, não só a melhoria da questão social, como também a questão ambiental, minimizando a venda de terras para pecuaristas que tendem a degradar as áreas (SILVA, 2012).

A partir de análises, existem práticas governamentais para visualizar se houve a criação de uma barreira adicional no controle efetivo do desmatamento na Amazônia (FEARNSIDE, 2001). Estas ações são realizadas devido ao uso da terra de forma inadequada nos lotes, onde muitos dos assentados não visam produzir de forma equilibrada, desrespeitando os limites estipulados em lei. Para Leite et al. (2004) o impacto de um Assentamento Rural ao meio ambiente, não são considerados iguais, estão relacionados tanto ao processo de criação quanto às condições econômicas, políticas, sociais e ambientais, que afetam a vida das famílias assentadas e o entorno dos Assentamentos, variando conforme a região em que é implantado.

Em grande maioria os problemas decorrentes dos impactos em áreas assentadas decorrem da falta de fiscalização e eficácia de políticas públicas que assegurem a adaptação dos assentados a novas áreas. Como fator agravante tem-se um exemplo de casos especiais, o uso de recursos disponíveis em reservas "sensíveis" para geração de renda pelas famílias (LEITE et al., 2004). Essa situação gera em casos isolados, práticas negativas por parte dos assentados com finalidade de sustento das famílias. Segundo Alencar et al. (2016), as principais causas do desmatamento nos assentamentos no bioma Amazônia são a pecuária extensiva e a extração madeireira ilegal, seguidas pela prática de agricultura de corte e queima.

\section{Geoprocessamento, Sistema de Informação Geográfica e Uso da Terra}

O Geoprocessamento e o Sensoriamento remoto são importantes ferramentas nos estudos voltados à observação do meio ambiente, às quais proporcionam a visualização de possíveis modificações no decorrer dos anos em uma mesma área. Segundo Novo (1992) o sensoriamento remoto consiste na interpretação de imagens de satélite captadas por sensores (satélites, radares, fotografias aéreas, etc.). Estas imagens auxiliam a observar distintas variáveis podendo ser utilizadas para a análise ambiental de uma área.

Desta forma, esta ferramenta possibilita um enriquecimento na análise de características relacionadas à redução de cobertura vegetal. Geralmente estas análises são realizadas através de séries temporais que consistem na observação de informações quantitativas ao longo de um determinado período (ANTUNES; CARDOSO, 2015). O uso e ocupação da terra é um exemplo de diversas variáveis avaliadas a partir de procedimentos de sensoriamento remoto (CARDOSO; FARIA, 2010).

Os estudos de Mapeamento Temático visam a caracterizar e entender a organização do espaço, como base para o estabelecimento de ações e estudos futuros (MEDEIROS; CÂMARA, 2001). As geotecnologias têm contribuído cada vez mais com informações sobre a superfície terrestre e são produtos de pesquisas relacionadas ao uso e ocupação do solo em áreas de preservação 
permanente (ROMAGNOLI et al., 2012), a dinâmica de desflorestamento (PIONTEKOWSKI et al., 2014) e a proteção ambiental (MASCARENHAS et al., 2009), por exemplo.

O Sistema de Informação Geográfica (SIG), por sua vez, podem ser definidos como sistemas de informações construídos especialmente para armazenar, analisar e manipular dados geográficos (CÂMARA et al., 1996). Estes sistemas comportam diferentes tipos de dados (arquivos vetoriais e raster) e aplicações, em várias áreas do conhecimento.

Pode-se utilizar o SIG em diversas áreas. Exemplos são otimização de tráfego, controle cadastral, gerenciamento de serviços de utilidade pública, demografia, cartografia, administração de recursos naturais, monitoramento costeiro, controle de epidemias e planejamento urbano (CÂMARA et al., 1996).

A partir do avanço das tecnologias da difusão dos computadores desenvolveram-se também os sistemas de informação geográfica, cujos, foram acrescentados técnicas que contribuíram para a melhoria do processo de construção de mapas e da possibilidade de análises sobre a dinâmica de utilização da terra (IBGE, 2013).

Costa e Rocha (2010) consideram que o uso de modelos estatísticos em conjunto com o uso de computadores, e a incorporação de técnicas de sensoriamento remoto em estudos, contribui para obtenção de um melhor produto da interpretação analógica de fotografias aéreas e imagens na identificação de padrões de uso da terra. Dentro deste contexto caracterizou o momento da disponibilidade de produtos de satélites imageadores da terra como marco de uma nova era dos estudos de Uso da Terra (IBGE, 2013).

As informações obtidas através de imagens orbitais são importantes fontes básicas para o mapeamento do uso da terra, pois estes dados expõem os aspectos referentes às áreas analisadas. E dependendo do tipo de satélite pode-se ter uma visão mais direta da realidade em que encontra uma região. Nos ambientes rurais, a partir da interpretação das imagens podemos identificar o tipo de uso de cada área, por meio do monitoramento das mudanças que ocorrem, como a substituição de mata por pastagem (LEMES et al., 2009).

\section{Materiais e Métodos}

\section{Descrição da área de estudo}

A área de estudo compreende o Projeto de Assentamento Matupi (PA Matupi), localizado no município de Manicoré, microrregião do Vale do Rio Madeira, sul do Estado do Amazonas. O

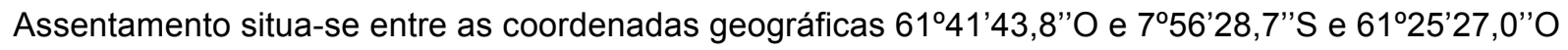
e 7051'10,8's (Figura 1).

O projeto de Assentamento Matupi foi criado em 1992, com uma área de $34.889,77$ ha, pelo Instituto Nacional de Colonização e Reforma Agrária (INCRA) e o processo de ocupação ocorreu em julho de 1995. O assentamento localiza-se a $200 \mathrm{~km}$ da sede do município de Manicoré. Possui uma capacidade de assentamento de 538 parcelas e teve aproximadamente 346 famílias assentadas na época de sua implantação (SILVA, 2012). 


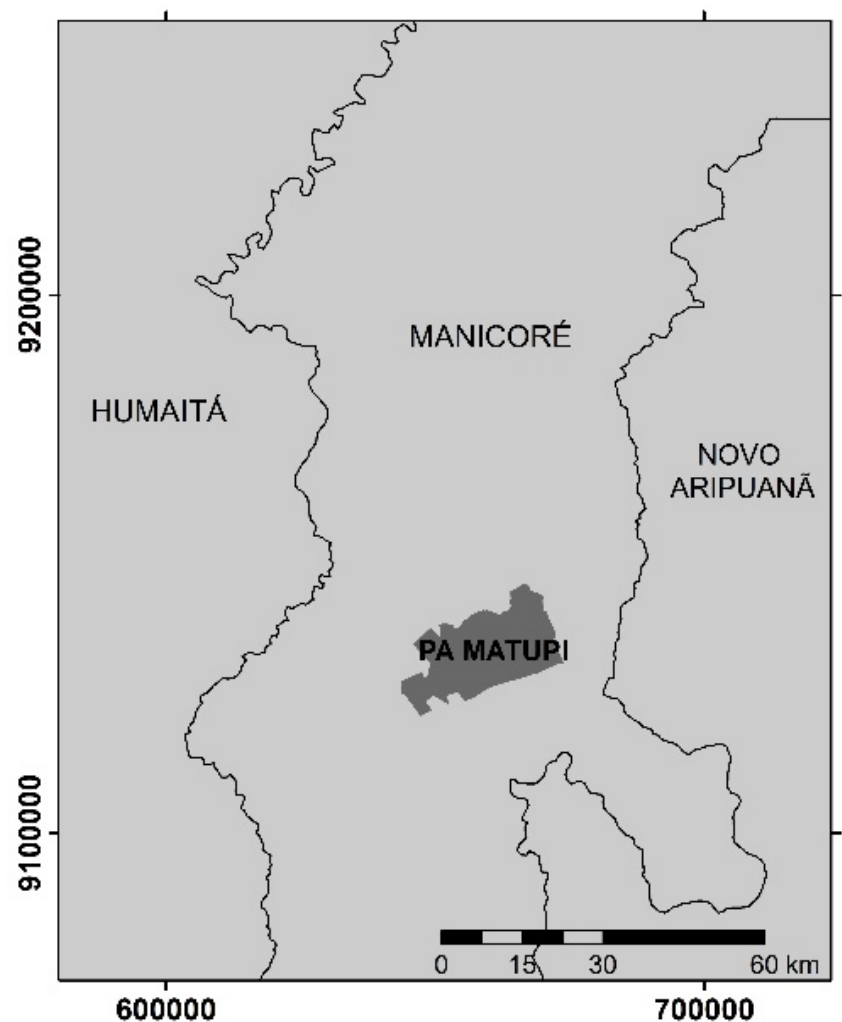

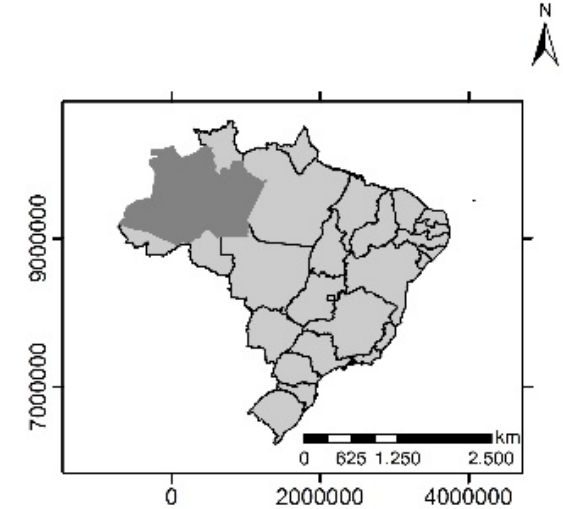

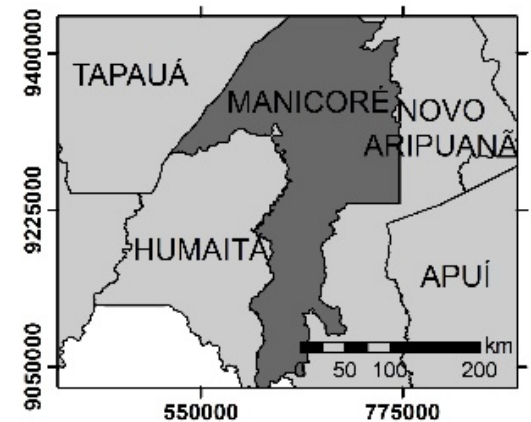

Sistema de Projeção:

Universal Transversa de Mercator (UTM)

Datum: SIRGAS 2000

Figura 1 - Localização da área de estudo: Projeto de Assentamento Matupi (PA Matupi).

Fonte: Leal et al. (2017)

\section{Aquisição de dados de satélites}

Como procedimento metodológico, optou-se pelas imagens do satélite Landsat-8 sensor OLI, disponibilizadas gratuitamente no catálogo de imagens do Instituto Nacional de Pesquisas Espaciais (INPE), com seguinte órbita-ponto (231/065), que compreende a área analisada do estudo.

No processo de extração, foram aplicados critérios para a escolha dos arquivos digitais, sendo um destes, a data de aquisição do satélite. Para obter uma cena de boa qualidade da Amazônia tendo como fator o período analisado, foram selecionados os dados do ano de interesse (correspondentes aos meses de julho, agosto e setembro), com cobertura mínima de nuvens e melhor visibilidade, além de uma adequada qualidade radiométrica (INPE, 2013). A data de aquisição das imagens de satélites coletadas foi de 25/07/2015, ou seja, encontra-se no período seco na porção sul do estado do Amazonas.

\section{Procedimentos metodológicos}

Através do software Q GIS Desktop 2.8.1 foram reprojetadas todas as bandas correspondentes da imagem da área de estudo para o datum SIRGAS 2000, UTM, Zona 20S. É necessário adotar este processo, porque as mesmas já se encontravam projetadas para o Hemisfério Norte, como no caso, para o datum WGS 84 (World Geodesic System), desta forma necessitando o ajuste cartográfico para o sistema de projeção padrão. 
Após a reprojeção das imagens foi realizada a composição multiespectral da imagem, com as bandas espectrais 4 (visível vermelho), 5 (infravermelho próximo) e 6 (infravermelho médio/SWIR) ambas com resolução espacial de $30 \mathrm{~m}$, e no formato geotiff o qual permite embutir informações das coordenadas geográficas em um arquivo tiff. Com o método utilizado, uma melhor visualização foi obtida por parte do processador do comportamento dos pixels na imagem para fins de classificação. Por conseguinte, obteve-se como produto uma imagem de composição colorida (Figura 2).

Optou-se por essa composição de bandas espectrais do satélite Landsat $8 \mathrm{OLI}$, pois a banda 4 é útil na observação do contraste dos solos com corpos hídricos e para mapear a vegetação que foi queimada de determinadas áreas. A banda 5 mede o infravermelho próximo e é extremamente importante para obtenção de índices, bem como Normalized Difference Vegetation Index (NDVI), que mede as condições de vegetação com precisão. A banda 6, é particularmente útil em estudos geológicos para diferenciar terra molhada da terra seca e identificar as rochas e solos que se confundem em outras bandas (NASA, 2013).

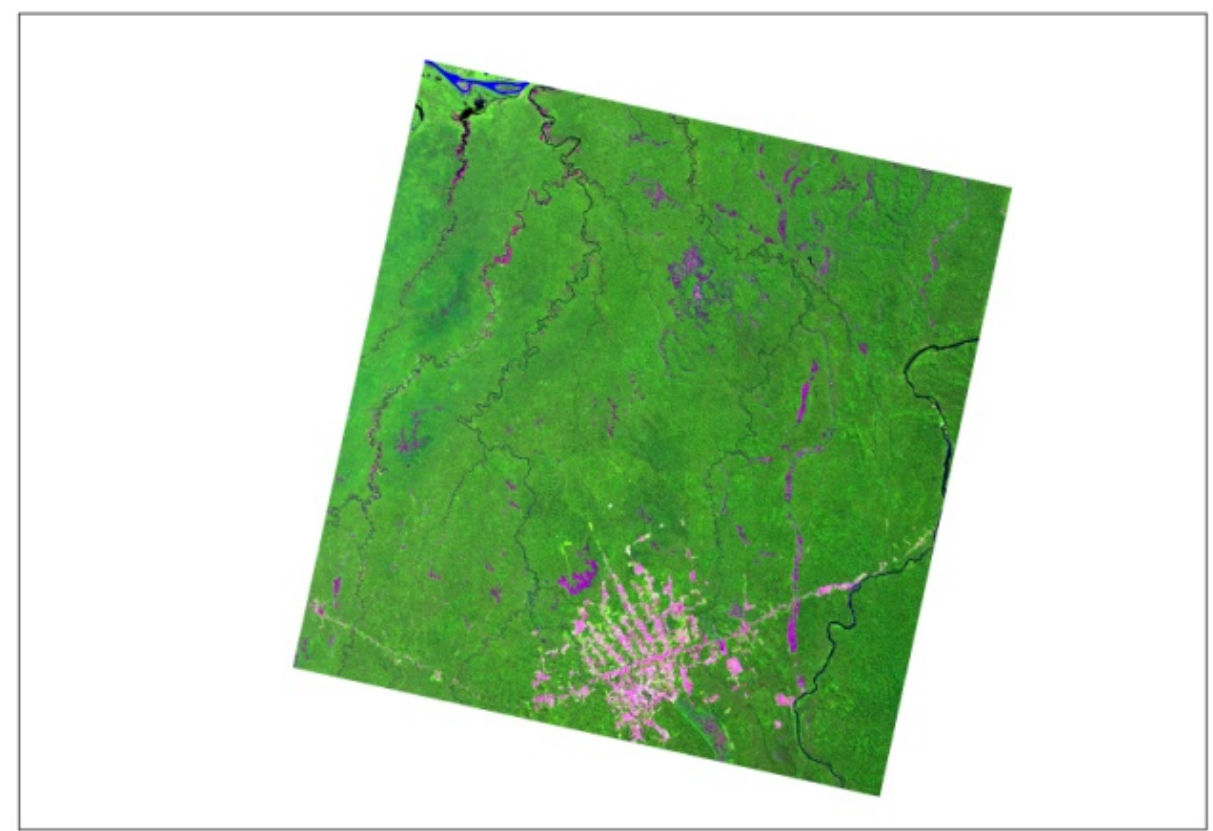

Figura 2 - Imagem na composição multiespectral, bandas 6, 5 e 4 .

Durante o trabalho foi realizado a fusão da composição colorida (RGB), com resolução espacial de 30 metros, com a banda 8 (banda pancromática), de resolução espacial de 15 metros através dos algoritmos Orfeo Monteverde contido no software utilizado. Neste algoritmo são encontradas ferramentas que fusionam imagens com o intuito de aumentar a sua resolução espacial. A partir do uso deste algoritmo obteve-se como produto, uma imagem com resolução espacial de $15 \mathrm{~m}$ colorida.

Como resultado deste processo, é possível observar segundo Soares et al. (2015) que executou um trabalho semelhante a este, ganhos em detalhes em relação à imagem multiespectral, como vegetação com cores mais vivas e tons naturais, sendo que a vegetação densa apresenta tom verde escuro e textura rugosa contrastando com a vegetação rasteira de áreas regeneradas com verde claro e textura suave próximo da realidade, coloração magenta que caracteriza áreas de solo exposto (Figura 3).

Após a composição das bandas e a fusão das mesmas, procedeu-se o recorte da área de estudo, que se dispõe do intuito de minimizar os erros no trabalho, pois seria difícil realizar a classificação digital na extensão total da imagem sem a probabilidade de um erro elevado. 


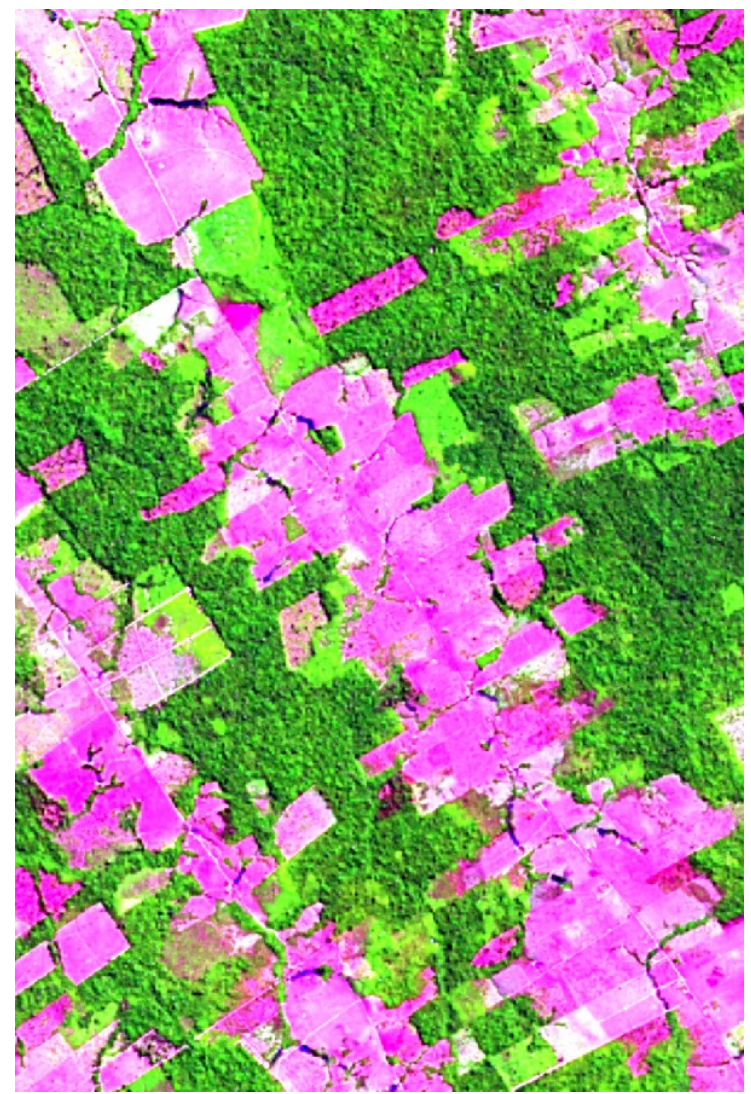

Figura 3 - Imagem Landsat 8 com resolução espacial de 15m, RGB 6,5 e 4.

O recorte foi executado com o auxílio de um arquivo do tipo shapefile (camada vetorial da extensão total do Assentamento) disponível no site do INCRA, onde como produto do processo obteve-se a área total do PA Matupi. Foram adotadas as classes de Floresta, Pastagem Abandonada e Pastagem que serviram como ponto alvo na coleta dos pixels nas imagens para a classificação digital. Coletaram-se 20 amostras de pixels dos polígonos para cada classe pré-estabelecida, para fins de minimização dos erros no procedimento realizados no software Q GIS Desktop 2.8.1.

Realizou-se a Classificação Supervisionada Digital, pelo método Máxima Verossimilhança e a seguir realizou-se o cálculo da acurácia geral do mapa. A confiabilidade científica do estudo é determinada pela Acurácia Geral do mapa. A mesma é expressa através do índice de exatidão global, de acordo com Ponzoni e Rezende (2002), Equação 1.

$$
\mathbf{G}=\boldsymbol{\Sigma} \mathbf{n i i} / \mathbf{n}
$$

Em que: G é a exatidão global; nii é o número de elementos da diagonal da matriz de confusão; e $\mathbf{n}$ corresponde ao número total de observações.

\section{Resultados e Discussão}

A soma número de elementos da diagonal da matriz de confusão é apresentada na Equação 2.

$$
\mathrm{nii}=22840+12+45=22897
$$

No total de 22953 observações, este valor significa que $99 \%$ dos pares de observações são concordantes (Equação 3).

$$
\text { G }=22897 / 22953=0,997
$$


Ou seja, representa 99,7\% de acurácia na classificação digital da imagem, logo é visível que as amostras de pixels de cada classe foram bem selecionadas, por isso há um valor representativo de acerto nos pares concordantes referentes às classes temáticas das imagens, dos testes que foram realizadas a cada classe. De acordo com o estudo de Landis e Koch (1977) a classificação realizada é considerada como excelente, uma vez que o valor do índice de exatidão global está entre o intervalo posto pelos autores, isto é, de 81 a 100\%. Além disso, a exatidão global calculada está dentro do padrão de $85 \%$ estabelecido por Jensen (1986). A seguir foi calculada área para cada uma das classes estabelecidas.

Com os procedimentos realizados, obteve-se o mapa temático de Uso e Ocupação da Terra na escala de 1:156.753 do Projeto de Assentamento Matupi, para o ano de 2015 (Figura 4).

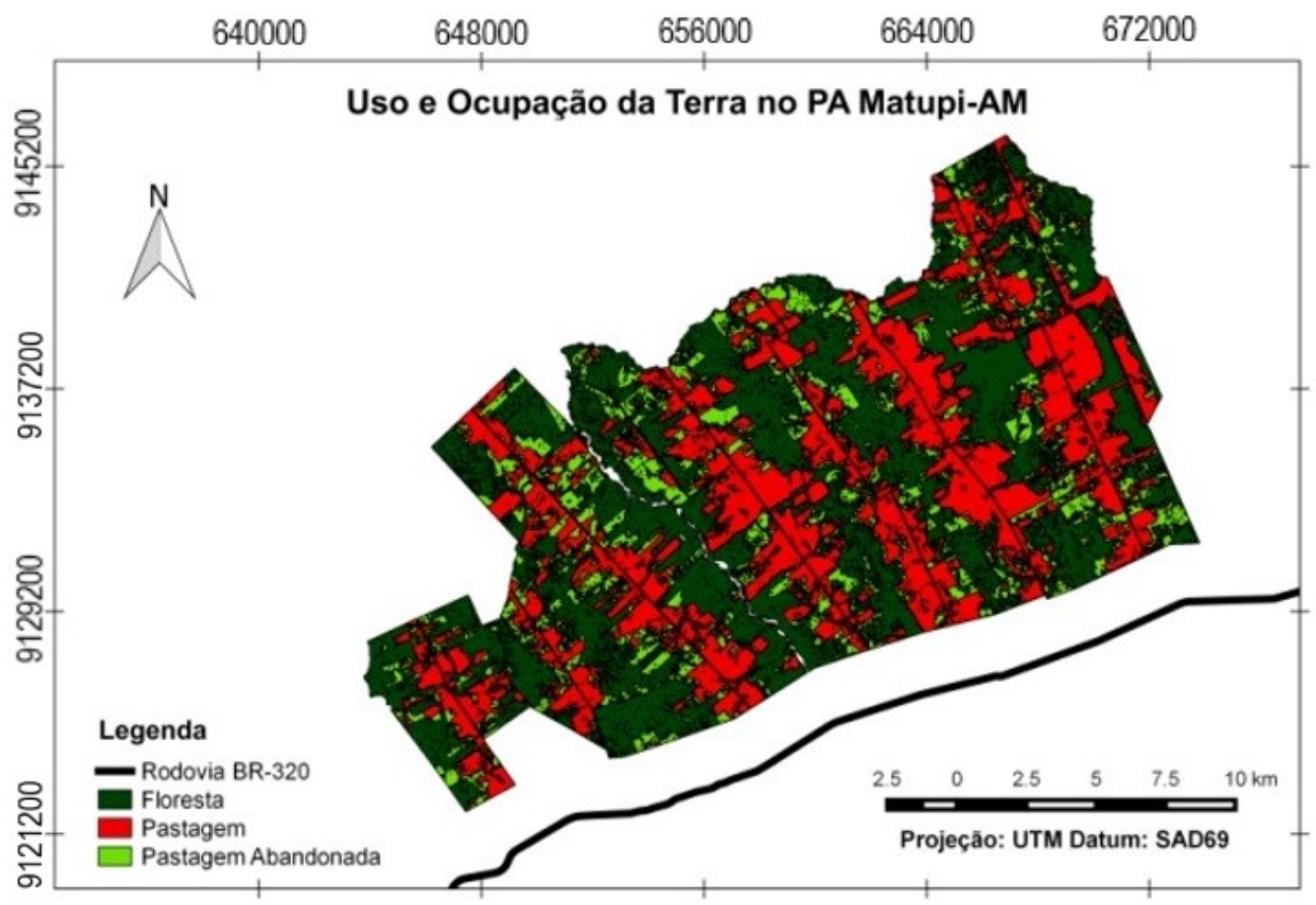

Figura 4 - Uso e Ocupação da Terra no PA Matupi.

Com a ferramenta (calculadora de campo) contida no software QGis, quantificaram-se as áreas de cada classe obtida na classificação digital, e com o auxílio do programa Microsoft Office Excel 2007, alcançaram os respectivos valores referente as áreas das mesmas.

A cobertura vegetal do Projeto PA Matupi é caracterizada pela Floresta Ombrófila Aberta, que apresentou a maior cobertura com $42,35 \%$ de toda a área, aproximadamente $14.783,23$ ha (Tabela 1).

Tabela 1 - Distribuição das áreas por classes e suas respectivas áreas em hectare (ha).

\begin{tabular}{lccl}
\hline Pastagem & Pastagem Abandonada & Floresta & Total \\
\hline 11941,29 & 8178,54 & 14783,23 & 34903,10 \\
\hline
\end{tabular}


Expressando as outras classes da tabela em função da distribuição espacial da área em estudo, é possível verificar regiões com alterações de suas características naturais. A mudança de atividade econômica que passou da agricultura para a pecuária também pode estar relacionada com o aumento das áreas de florestas convertidas em uso da terra (SILVA et al., 2011). Em função deste fator, a classe Pastagem apresenta-se com $34,22 \%$ apresentando $11.941,29$ ha, e a classe Pastagem Abandonada com $23,43 \%$ cerca de $8.178,54$ ha da área total.

Este valor elevado expresso para Pastagem e Pastagem abandonada, tem por consequência, a principal atividade geradora de renda a população local, a Pecuária. $O$ uso da terra da região é caracterizado por uma porção de pecuária mais característica das regiões de fronteira do desmatamento (km 180) (CENAMO et al., 2011).

Ressalta-se outro fator para a alteração da cobertura vegetal local, cujo mesmo, está relacionado direta ou indiretamente, as estradas da região, assim como a BR 319 e BR 230 (principal via de acesso ao PA Matupi) as quais servem de canalizadores do processo migratório, do crescimento demográfico e dos adensamentos urbanos decorrentes (DINIZ et al., 2009). Por consequência, a Pecuária foi inserida ao local por migrantes que vieram de outras regiões do país, cujos mesmos, para se locomoveram para esta região tiveram incentivos de programas governamentais. Logo se implantou esta prática ao local e por condições favoráveis, a atividade vem se desenvolvendo, contribuindo para o aumento do desflorestamento da vegetação local.

Segundo o Novo Código Florestal, todo imóvel rural localizado na Amazônia Legal deve manter $80 \%$ de área com cobertura de vegetação nativa, a título de Reserva Legal (BRASIL, 2012). Todavia, a Instrução Normativa $n^{\circ}$. 2 do Ministério do Meio Ambiente, estabelece que os assentamentos criados até 22 de julho de 2008, a Reserva Legal será constituída com a vegetação existente até a data referida (MMA, 2014). Ou seja, o limite de $80 \%$ não é aplicado ao PA Matupi, já que foi criado antes de 2008.

Mesmo assim, o PA Matupi, de uma forma geral, encontra-se bastante alterado. Como mostra o estudo, o Assentamento possui $34,22 \%$ de área de Pastagem, ou seja, um valor bastante expressivo comparado a outros Assentamentos localizados no Amazonas, que, por serem, em sua maioria $(65 \%)$ de base extrativista, não colaboram com o aumento do desmatamento (ALENCAR et al., 2016).

\section{Conclusão}

Embora ainda mantenha parte de suas áreas florestais preservadas, foi possível constatar que o uso e ocupação da terra no PA Matupi é caracterizado, em sua maioria, por áreas de pastagens. Uma das explicações para esta informação consiste na substituição da agricultura familiar pela pecuária, principal atividade econômica no assentamento, e responsável pela alteração de suas características naturais. As vias de acesso terrestres, assim como a BR - 230 (Transamazônica), também contribuíram indiretamente para a implantação de pastagens e o resultante é um agravamento de desflorestamento no PA Matupi, já que migrantes de outras regiões do país inseriram a pecuária no local. Desta forma, é possível concluir que as variáveis que explicam a degradação florestal em assentamentos rurais, como a pecuária e abertura de estradas, atuam em conjunto, criando assim uma condição favorável para o seu desflorestamento. 


\section{Referências}

ALENCAR, A. et al. Desmatamento nos assentamentos da Amazônia: histórico, tendências e oportunidades. Brasília: IPAM, 2016.

ANTUNES, J. L. F.; CARDOSO, M. R. A. Uso da análise de séries temporais em estudos epidemiológicos. Epidemiol. Serv. Saúde, Brasília-DF, v. 23, n. 3, p. 565-576, jul./set. 2015.

BRASIL. Ministério do Meio Ambiente. Plano de Ação para prevenção e controle do desmatamento na Amazônia Legal (PPCDAm). Brasília, 2013.

BRASIL. Lei $n^{\circ} 12.651$ de 25 de maio de 2012. Institui o Novo Código Florestal Brasileiro. Brasília: DOU de 28/5/2012.

BRANDÃO JÚNIOR, A.; SOUZA JÚNIOR, C. Desmatamento nos assentamentos de Reforma Agrária na Amazônia. O Estado da Amazônia, n. 7, p. 1-4, Jun. 2006.

CALANDINO, D.; WEHRMANN, M.; KOBLITZ, R. Contribuição dos assentamentos rurais no desmatamento da Amazônia: um olhar sobre o Estado do Pará. Desenvolvimento e Meio Ambiente, Curitiba-PR, v. 26, n.1, p. 161-170, Jul./Dez. 2012.

CÂMARA, G. et al. Anatomia de Sistemas de Informação Geográfica. Rio de Janeiro: Divisão de Processamento de Imagens, 1996.

CÂMARA, G. et al. Spring: Integrating Remote Sensing and GIS by Object-Oriented data modelling. Computersand Graphics, v. 20, n. 3, p. 395-403, July. 1996.

CARDOSO, C. A. L.; FARIA, F. S. R. O uso do geoprocessamento na análise ambiental como subsídio para a indicação de áreas favoráveis a criação de unidade de conservação para o uso sustentável do minhocuçu Rhinodrilus alatus. E-Scientia, Belo Horizonte, v. 3, n. 1, p. 1-26, 2010.

CENAMO, M. C.; CARRERO, G. C.; SOARES, P. G. Redução de emissões do desmatamento e degradação florestal (REDD+): estudo de oportunidades para a região sul do Amazonas. Manaus: IDESAM, 2011.

COSTA, F. R. da; ROCHA, M. M. Geografia: conceitos e paradigmas - apontamentos preliminares. Revista GEOMAE: geografia, meio ambiente e ensino, Campo Mourão, PR, v. 1, n. 2, p. 25-56, jul./ago. 2010.

DINIZ, M. B. et al. Causas do desmatamento da Amazônia: uma aplicação do teste de causalidade de Granger acerca das principais fontes de desmatamento nos municípios da Amazônia Legal brasileira. Nova Economia, Belo Horizonte, v. 19, n.1, p.121-151, Jan./Abr. 2009.

FEARNSIDE, P.M. Land-tenure issues as factors in environmental destruction in Brazilian Amazonia: the case of southern Pará, World Development, Oxford, v. 29, n. 8, p. 1361-1372, August. 2001.

GIRARDI, E.P.; FERNANDES, B.M. A luta pela terra e a política de assentamentos rurais no Brasil: a reforma agrária conservadora. Agrária, São Paulo, n. 8, p. 73-98, Jan./Jun. 2008.

INSTITUTO BRASILEIRO DE GEOGRAFIA E ESTATÍSTICA - IBGE. Manual Técnico de Pedologia. 2. Edição. Rio de Janeiro-RJ: IBGE, 2007.

INSTITUTO BRASILEIRO DE GEOGRAFIA E ESTATÍSTICA - IBGE. Manual Técnico em Geociências. 3. Edição. Rio de Janeiro-RJ: IBGE, 2013.

INSTITUTO NACIONAL DE COLONIZAÇÃO E REFORMA AGRÁRIA - INCRA. Assentamentos Rurais. 2016. Disponível em: </http://www.incra.gov.br/assentamento>. Acesso em: 24 Jan. 2016. 
INSTITUTO NACIONAL DE PESQUISAS ESPACIAIS - INPE. Projeto PRODES digital: Programa de cálculo do desflorestamento da Amazônia, 2015. Disponível em: < http://www.obt.inpe.br/prodes>. Acesso em: 12 Dez. 2015.

JENSEN, J. R. Introductory digital image processing. Englewood Cliffs: Prentice - Hall, 1986.

LANDIS, J. R.; KOCH, G. G. The measurement of observer agreement for categorical data. Biometrics, v. 33, n. 1, p. 159-174, 1977.

LE TOURNEAU, F. M.; BURSZTY, N. M. Assentamentos rurais na Amazônia: contradições entre a política agrária e a política ambiental. Ambiente \& Sociedade, Campinas-SP, v. 13, n. 1, p. 111-130. Jan./Jun. 2010.

LEAL, M. L. M. et al. Uso da terra e a legislação florestal no Projeto de Assentamento Matupi, AM. Boletim de Geografia, Maringá-PR, v. 35, n.1, p. 122-133, Ago. 2017.

LEITE, S. et al. Impactos dos assentamentos: um estudo sobre o meio rural brasileiro. $6^{\text {a }}$ Edição. São Paulo: UNESP, 2004.

LEMES, S. S.; DOS SANTOS, K. R.; LIMA, C. V. de. Utilização de imagens de alta resolução espacial para análise do uso da terra e de processos erosivos na cabeceira de drenagem do Córrego Gueirobal em Anápolis (GO). In: SIMPÓSIO BRASILEIRO DE SENSORIAMENTO REMOTO, 14., 2009, Natal. Anais eletrônicos... , São José dos Campos-SP: INPE, 2009. p. 5909-5916.

MACEDO, M.A.; TEIXEIRA, W. Sul do Amazonas, nova fronteira agropecuária? O caso do município de Humaitá. In: SIMPÓSIO BRASILEIRO DE SENSORIAMENTO REMOTO, 14., 2009, Natal. Anais eletrônicos... , São José dos Campos-SP: INPE, 2009. p. 5933-5940.

MASCARENHAS, L. M. de A.; FERREIRA, M. E.; FERREIRA, L. G. Sensoriamento Remoto como instrumento de controle e proteção ambiental: Análise da cobertura vegetal remanescente na bacia do Rio Araguaia. Sociedade \& Natureza, Uberlândia, v. 21, n. 1, p. 5-18, Abr. 2009.

MEDEIROS, J. S. de; CÂMARA, G. Geoprocessamento para projetos ambientais. In: CÂMARA, G.; DAVIS, C.; MONTEIRO, A. M. V. Introdução à ciência da geoinformação. $2^{\text {a }}$ Edição. São José dos Campos: INPE, 2001. p. 289-320.

MINISTÉRIO DO MEIO AMBIENTE - MMA. Instrução Normativa $n^{\circ} .2$ de 6 de Maio de 2014. Dispõe sobre os procedimentos para a integração, execução e compatibilização do Sistema de Cadastro Ambiental Rural - SICAR. Brasília, 2014.

NASA LANDSAT SCIENCE. Landsat 8. 2016. Disponível em: <http://landsat.gsfc.nasa.gov/?page id=4071>. Acesso em: 17 maio de 2016.

NASA LANDSAT SCIENCE. Landsat 8 Bands. 2013. Disponível em: <http://landsat.gsfc.nasa.gov/?page_id=5377 >. Acesso em: 09 maio de 2016.

NOVO, E.M.L.M. Sensoriamento Remoto: princípios e aplicações. Ed. São Paulo: Edgard Blücher, 1992.

PIONTEKOWSKI, V. J.; MATRICARDI, A. T.; PEDLOWSKI, M. A.; FERNANDES, L. C. Avaliação do desmatamento no estado de Rondônia. Floresta e Ambiente, Seropédica-RJ, v. 21, n. 3, p. 297-306, Jul./Set. 2014.

PONZONI, F. J.; REZENDE, A. C. P. Influência da resolução espacial de imagens orbitais na identificação de elementos da paisagem em Altamira-PA. Revista Árvore, Viçosa, v. 26, n. 4, p.403410, 2002. 
ROMAGNOLI, I.; PIROLI, E. L.; ZANATA, J. M.; GIMENES, G. R. Geoprocessamento aplicado na análise do uso da terra das áreas de preservação permanente dos corpos d'água da Microbacia do Rio da Prata - SP. Revista Geonorte, Manaus-AM, v.2, n. 4, p. 1529-1539, Jun. 2012.

SILVA, V. V. da; VETTORAZZI, C. A.; PADOVANI, C. R. Assentamento rural e a dinâmica da paisagem. In: XV SIMPÓSIO BRASILEIRO DE SENSORIAMENTO REMOTO, 15., 2011, Curitiba-PR. Anais eletrônicos..., São José dos Campos-SP: INPE, 2011. p. 7000-7006.

SILVA, V. V. Impactos das atividades produtivas na dinâmica da paisagem do assentamento Matupi, estado do Amazonas. 2012. 117p. Tese (Doutorado em Ecologia Aplicada) - Escola Superior de Agricultura Luiz de Queiroz, Universidade de São Paulo, Piracicaba/SP, 2012.

SOARES, R. B.; SOARES, C. B. S. S.; COSTA, J. A. L. Aplicação de técnica de fusão em imagens Landsat8/OLI. In: SIMPÓSIO BRASILEIRO DE SENSORIAMENTO REMOTO, 17., 2015, João Pessoa-PB. Anais eletrônicos... , São José dos Campos-SP: INPE, 2015. p. 4836-4843.

WALKER, R.T.; MORAN, E.; ANSELIN, L. Deforestation and cattle ranching in the Brazilian Amazon: external capital and household process. World Development, Oxford, v.28, n.4, p.683-699, April. 2000 . 